\title{
Semblanza judía. Historias de judíos en torno a la inmigración al Perú
}

\author{
Patricia Cadenas Erazo \\ Universidad Nacional Mayor de San Marcos \\ mpatce@gmail.com
}

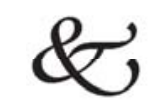

Presentamos una serie de relatos en torno a las circunstancias de la inmigración y del establecimiento judío en el Perú durante los siglos diecinueve y veinte, destacando la idoneidad de la historia oral para reconstruir la historia de la presencia judía en este país y proponer el estudio de la identidad judía (judeidad) peruana en términos de una religiosidad que incluya, de manera amplia y continua, tanto a los judeoconversos ${ }^{1}$ o marranos de tiempos coloniales como a los judíos mestizos de tiempos actuales.

Semblanza judía constituye la narración de un conjunto de historias orales sobre la inmigración judía a Sudamérica, durante la segunda mitad del siglo diecinueve en una pequeña proporción y, en gran medida, a lo largo del siglo veinte. Estas historias han sido registradas hace más de diez años, en 1999, y fueron relatadas por sus propios protagonistas, la mayoría de ellos, judíos europeos que se radicaron en Perú.

Para esta nota, hemos seleccionado un conjunto de fragmentos, extraídos de dichas historias. De esta manera, presentamos una caracterización de la colectividad judía afincada en Perú, tomando en cuenta las circunstancias de su arribo, establecimiento y desenvolvimiento en el territorio peruano; pero, sobre todo, transmitiendo las condiciones de la emigración en sus pueblos y ciudades de origen en el caso de los sobrevivientes a la Segunda Guerra Mundial.

Asimismo, esta selección de historias abarca el relato de aquellos otros judíos cuyas circunstancias de arribo, mucho más antiguas, se remontan a las últimas décadas del siglo diecinueve y marcan el inicio de la organización institucional judía en Perú con la formalización de la creación de la Sociedad Hebrea de Beneficencia, el primero de julio de 1873 (Trahtemberg 1987: 51).

1 Judíos obligados a convertirse al cristianismo en tiempos de la Inquisición española, constituidos, por esta misma razón, en cristianos nuevos aunque bajo sospecha constante de mantener sus prácticas judaizantes en forma secreta (criptojudaísmo). 


\section{Patricia Cadenas Erazo}

En este último caso, la contribución de los familiares descendientes de los judíos arribados durante la segunda mitad del siglo diecinueve es igualmente significativa, ya que permite extender hasta periodos decimonónicos los linderos temporales de la inmigración judía a tierras peruanas.

De esta manera, por referencias de tercera generación (E1)2, nos enteramos de algunos pormenores de la llegada de Natasius Hurwitz, presidente, en 1873, de la primera Junta Directiva de la Sociedad Hebrea de Beneficencia en Perú, país al cual vino luego de una estadía en los Estados Unidos.

Natasius Hurwitz salió de Topolinken, Alemania, junto a otro hermano, siendo ambos muy jóvenes. Se embarcó así rumbo a Nueva York, ofreciendo sus servicios a bordo para desempeñarse en el trabajo doméstico. La llegada a Norteamérica coincidió con los momentos en que aparentemente empezaba la Guerra de Secesión, y estos jóvenes, Natasius con su hermano, decidieron participar en la lucha por la causa norteña de la libertad, integrando las filas que apoyaban a Lincoln, en contra de la segregación.

Al finalizar la guerra, el espíritu insaciable de Natasius lo impulsó a emigrar al Sur, atraído por las noticias de que "en estos lugares había oro". Una vez asentado en Perú, estableció una tienda de semillas con fines agrícolas, viviendo no precisamente de grandes riquezas, sino tan sólo de su trabajo y esfuerzo personal.

Por medio de la misma fuente, también, sabemos de Jacobo Hurwitz, el penúltimo de los doce hijos de Natasius, quien nació en Perú en 1901 y desarrolló una intensa actividad intelectual y política que lo llevó a participar de la creación de la Universidad Popular Manuel Gonzales Prada así como a vincularse con el Partido Comunista Peruano y con su fundador ${ }^{3}$. Sus estudios de pedagogía en San Marcos se vieron interrumpidos al ser deportado por el gobierno de Leguía, pasando a Panamá, Cuba y, luego, a México, donde permaneció por más de treinta años.

A caballo entre historia autobiográfica y ficción, algunos textos, como los de Isaac Goldemberg (Goldemberg 1980, 1992, 2001), nos dan cuenta de la inmigración judía durante las primeras décadas del siglo veinte, narrando las experiencias de algunos inmigrantes judíos y sus problemas al tratar de adaptarse al Perú, a través de la descripción de paisajes y hechos ficticios pero cotidianos que pueden parecer, a veces, muy familiares y otras, tan alejados y desconocidos, configurando justamente la metáfora del judío errante que ha caracterizado no sólo la historia de la inmigración judía en el mundo sino también en Perú como se desprende de la experiencia de los Hurwitz.

2 Entrevistado 1, San Isidro, Lima, Perú, 27 noviembre de 1998, 4 y 11 de junio de 1999.

3 José Carlos Mariátegui, “El Amauta”, fundó el Partido Comunista Peruano en 1928. 
Como en el caso de sus correligionarios de principios del siglo veinte, el proceso de adaptación de gran parte de los judíos sobrevivientes al holocausto siguió, al principio, una ruta sinuosa que los llevó a recorrer distintos lugares antes de establecerse en alguna ciudad peruana. Estos judíos llegaron procedentes de Francia, Londres o de otros lugares de Sudamérica, como Bolivia, tras ser desplazados de sus lugares de origen en Europa.

Rusos, polacos, rumanos, alemanes empezaron a llegar por la década del cincuenta en adelante. Algunos, completamente solos, vinieron a encontrarse con parientes desconocidos, asentados hacía mucho antes en el territorio peruano, que los reclamaron y acogieron. Otros, en compañía, todavía, de sus familiares más cercanos, ingresaron a nuestro país para labrarse mejores condiciones de vida. A la evocación de sus pueblos natales, la nostalgia de un mundo totalmente diferente que ya no ha de volver se hace presente: Sería difícil tratar de explicar los recuerdos de mi infancia porque yo he nacido y vivido en un mundo que usted no conoce. No le puedo trans... No, no le puedo transcribir algo que usted no... no tiene noción de cómo es. Yo le hablo de un pueblo pequeño... Mmm... Quizás, tres a cuatro mil habitantes. La mitad de ellos eran judíos (E3) ${ }^{4}$.

Ésta es la primera respuesta a la pregunta sobre los recuerdos de la infancia en sus pueblos natales. Surge así la descripción de una villa europea cuyas imágenes transmiten un entorno muy religioso con un estilo de vida muy tradicional: Eh... La vida judía en los pequeños pueblos de Europa eran muy... eh... muy particular, muy especial. Un viernes, usted no sabe lo que era un día de fiesta, la gente cerraba los negocios, todo el mundo comenzaba cambiarse de ropa, salía para ir a rezar... Entonces, son vivencias que es dificil que usted las pueda vi... Las pueda en... Las pueda imaginar porque eso no existe aquí. Tal vez pudo haber visto alguna vez alguna película, en alguna película o algo así. Por eso, son dos mundos, son prácticamente dos planetas diferentes. Había una vida religiosa muy, muy intensa, aun para aquéllos que no eran especialmente religiosos. Pero el entorno, el entorno comunitario era religioso, muy, muy religioso (E3) .

Tales imágenes contrastan con los posteriores acontecimientos acaecidos entre 1939 y 1945. Las consecuencias de los mismos constituyeron una de las mayores tragedias de la humanidad por las víctimas resultantes, pero, además, generaron también una serie de desplazamientos demográficos que privaron a mucha gente del retorno a sus lugares de origen, sea porque encontraron tan sólo destrucción y desolación en ellos, sea porque ya no tenían a nadie cercano, a ningún pariente, a ningún amigo o conocido con quien seguir compartiendo las mismas actividades diarias, las ilusiones, los anhelos: Bueno, eh... Me acuerdo, los recuerdos que tengo de ella es que... A los nueve años, eh, me acuerdo

4 Entrevistado 3, Miraflores, Lima, Perú, 2 de junio de 1999.

5 Ídem. 
que... El día primero de septiembre, eh, comenzó la Segunda Guerra Mundial. Eso me acuerdo. A los nueve días, eh, a... antes que empezase, a comienzos de la guerra, ingresaron los rusos a nuestro pueblo. Y nos... nos han, nos han, me dicen que... es... es una... que mi familia... Un poco nos han, nos han robado y nos han... nos han quitado la casa, nos han obligado a un... a otro pueblo en el cual tu... Y, ahí, tuvimos que vivir durante la guerra, el año, hasta el año cuarenta y... (E4) ${ }^{6}$.

Esta guerra constituyó una experiencia en común que marcó y cambio el rumbo de la vida de muchos judíos europeos, quienes entendieron que el retorno a sus pueblos ya no iba a ser posible porque todo estaba destruido. Lo único que restaba y tenía sentido era comenzar de nuevo, buscar otros ambientes donde encontrar estabilidad, para lograr así el bienestar tan ansiado que, hacía unos pocos años atrás, parecía inexistente.

Los episodios anteriores a la emigración no están exentos de recuerdos sobre las escenas violentas que protagonizaron a lo largo de la guerra, varias de las cuales, evidentemente, están cargadas de hostilidad y hasta de un trato inhumano, propio de un estado demencial: $y$ ahí nos quedamos en una ciudad, Kipichinitz. Ésta ha sido Galitzia de Polonia, Galitzia. Ahí, [es]tuvimos, mmm, alojados en una casa que... de una familia, por supuesto, judía. Yo iba a trabajar, mi esposa igual, a trabajar. Yo tenía en aquella época veintiséis, veintisiete años. Y, un día de estos trabajos, me tocó ir a un coreo ${ }^{7 * 0 *}$, lavar los pisos y el director era un enano, un alemán que la pistola casi llega a la... al piso. En eso, me llama él a mí:-iOiga, judío desgraciado, ven acá!- [No ves tiene que haber ha sido] deportista, futbolista, boxeador, todo deportes, practiqué volei. Y... -i¿Cómo sabe, usted, hablar alemán?!-, me pregunta, él. Entonces, yo le contesté como es verdad. El alemán y judío son bien parecidos. Si uno escucha hablar yiddish, judío, el alemán vas a ver, eh, tiene un cuarenta, cincuenta por ciento que... Son casi iguales. Ya. Entonces, me dio una cachetada así fuerte y comencé a sangrar. Yo reaccioné rápido. Si yo le devuelvo a él la cuche, la, eh, cachetada, él no se levanta más, icon la cólera que he tenido, no! Comencé a llorarme y limpié la sangre y salí. Bueno, ésa es una primera. ${ }^{(\mathrm{E}){ }^{8}}$

Nuestro testigo transmite visiblemente, la impotencia que lo embarga, la cual es al mismo tiempo utilizada como única arma defensiva para evitar hacer mayor aún la crueldad de los soldados nazis. Pero ninguna como la que éste mismo relator y su esposa tuvieron que presenciar, la muerte de su pequeña hija, sin poder hacer absolutamente nada 'Bazán Coquis 1999): Después regresé y mi primera esposa dio a luz en una noche. Para ir traer a la partera, no se podía, tenía miedo para ir porque era prohibido, los judios, andar de noche. [Por ello, yo lo he hecho solo]. Y, en la mañana, vino la partera, le cortó el cordón. Y pasaron los

6 Entrevistado 4, San Isidro, Lima, Perú, 12 de junio de 1999.

$7^{* * *}$ Correo.

8 Entrevistado 8, Surquillo, Lima, Perú, 8 de julio de 1999. 
meses, los meses... La criatura era una hermosura: nació con ojos celestes como mi esposa, pelo rubio. Y... y llegó a tener dos años y meses, la criatura. iUn muñeco!, un muñeco era, eh. Y, eh, trabajo ya no hubo tanto porque hecho ocuparon, los alemanes, más de matanzas no, no daron trabajo. Pero como en... Nuestra casa estaba cerca de un mercado, mi esposa le hizo un mandil a la criatura y abrió una madera para que pueda pasar al mercado. Yo iba por los campesinos, pidiéndole, enseñando con la mano comida... Y me dieron, cada uno me dieron un... pedazo de queso, pan, cosas... Entres ellos, podía vivir de eso. $Y$ es así hemos vivido un par de meses, de ahí, ya. Y un día, cuando jugaba la criatura en el parque, patio con varias, eh, criaturas de su edad, entraron los alemanes y mataron todos los niños, entre ellos a mi hijita también. Nosotros nos... Enseguida nos hemos metido en el bunga... ¿Bungalow se dice, no? Ya. Y, después de tres días pasó el basurero y, y metió a todos en la carretilla de basura y los llevaron y no sabemos [dóndel para enterrarla (E8)9.

Frente a estos hechos, las víctimas de las hostilidades y persecuciones de la guerra sólo podían optar entre soportar impotentes, resignados hasta el instante que todo terminase, o morir, pues huir, para muchos de ellos, era simplemente imposible. La referencia de esto nos la hace un sobreviviente rumano: i¿Huir?! No... No había forma. No había forma de huir, porque no te dejaban. Ahí, está el detalle. Han habido muy pocos que han logrado escapar a los bosques y han actuado en las filas de los partisanos, que eran los guerrilleros contra los nazis... Sí han habido, pero desgraciadamente muy pocos (E7) ${ }^{10}$.

Distinta fue la suerte de otros practicantes judíos, los cuales se alistaron, según lo expresado anteriormente, como partisanos en las guerrillas de resistencia contra los ejércitos nazis de ocupación. En este punto, cabe anotar que uno de nuestros informantes también formó parte de ese grupo de guerrilleros.

Otra de las razones por las cuales los inmigrantes judíos lograron sobrevivir al holocausto fueron, en algunos casos, totalmente circunstanciales y casuales. Por lo general, las mujeres, los niños, los ancianos y los enfermos eran exterminados en los campos de concentración. Sin embargo, un golpe de suerte pudo desviar a algunos de este fatal destino: "Yo... Yo sobreviví gracias $a \ldots$.. $a$ una casualidad que, eh... De un transporte de tres mil personas que hemos llegado al campo. Fuimos esco... escogidos once personas, por lo cual hemos sobrevivido y todo el resto de la gente los han matado (E5) ${ }^{11}$.

Un ejemplo de ello sucedió en Auschwitz. La narración de uno de nuestros entrevistados deja ver cómo su condición etaria -en ese entonces, once añoslo salvó de la muerte segura, toda vez que no podía ser utilizado como mano

9 Ídem.

10 Entrevista 7, San Isidro, Lima, Perú, 3 de julio de 1999.

11 Entrevistado 5, San Isidro, Lima, Perú, 17 de junio de 1999. 


\section{Patricia Cadenas Erazo}

de obra para los trabajos en el campo de concentración: Bueno, el, el fin mío, principalmente, por la edad mía que yo tenía fue para experimentos médicos, porque yo era un niño y a mí no me necesitaban para trabajar. La otra gente ha entrado al campo para trabajar, para explotarlos, eh, físicamente y... con el trabajo; pero yo no tenía entonces ese objetivo. Yo tenía once años cuando entré al campo. Porque, a mí, no me necesitaban para trabajar. No habían niños en el campo (E5) ${ }^{12}$.

Quienes lograron huir, lo hicieron generalmente a través de la argucia, la mentira y el soborno pues no había otra forma de hacerlo. Pese a ello, la tarea no resultaba nada fácil. No faltaron quienes aceptaban las ofertas del bando contrario, es decir, de los nazis alemanes para denunciar la presencia de judíos ocultos en un lugar determinado y delatar así su verdadera identidad. En este caso, una de nuestras colaboradoras, se traslada a sus cinco o seis años de edad para relatarnos las dificultades de las circunstancias vividas, junto con su familia, en el gueto de Varsovia: (...) cinco años más adelante, en el año cuarenta y tres, cuarenta y cuatro, cuarenta y cinco, cuando yo ya tenía cinco, seis años... Y, entonces, sí, eh, que he pasado por momentos muy terribles en mi infancia, porque tuve que... Tuvimos que vivir un buen tiempo en el gueto de Varsovia, rodeados de nazis que, todos los días, mataban hombres, mujeres y niños. El gueto estaba rodeado por una gran muralla con guardias en los portones; prácticamente, nos dejaron sin comida, sin medicina, sin trabajo; y, poco a poco, seguían llegando los judíos en camiones hacia los trenes de carga para llevarlos a los campos de exterminio, campos de concentración donde se encontraban las cámaras de gas (E2) ${ }^{13}$.

$\mathrm{Y}$, a diferencia de los casos anteriores, señala su huida del gueto, en condiciones, prácticamente, milagrosas: Nuestro escape del ghetto de Varsovia fue milagroso, se podría decir. Mi padre consiguió un pase y mi madre se disfrazó de campesina y, a mí, me disfrazó de campesina. Me enseñaron a rezar el Padrenuestro y tuvimos que escaparnos como cristianos y tuvimos muchísima suerte, porque esto fue una madrugada en la cual, eh, mi padre pudo sobornar a uno de los guardias polacos no alemanes que eran colaboradores de los alemanes, inclusive, a las cuatro o cinco de la madrugada, hemos podido escaparnos como campesinos polacos. Nos, eh, refugiamos en tres casas de amigos de mis padres, que fueron amigos de mi padre durante su época de estudios universitarios. Eran casas de cristianos polacos que, también, eh, arriesgaron sus vidas para... para escondernos y hemos vivido en tres casas separadas, porque era muy peligroso estar juntos, ya que había otros polacos que sí denunciaban o recibían dinero de los alemanes por cada judíos que encontraban (E2) ${ }^{14}$.

Finalmente, una última voz $(\mathrm{E} 6)^{15}$, con raíces también polacas, clama por una mayor tolerancia y para que la tragedia y asesinatos masivos como los

\footnotetext{
12 Ídem.

13 Entrevistado 2, Surco, Lima, Perú, 24 de mayo de 1999.

14 Ídem.

15 Entrevistado 6, San Isidro, Lima, Perú, 25 de junio de 1999.
} 
llevados a cabo por alemanes nazis no vuelvan a suceder nunca más. Al mismo tiempo, nos da cuenta del coraje y valentía que guiaron a su madre, autora de la memoria, Escape a la vida (Karl 1999), para sobrevivir siempre al lado de sus pequeñas hijas, una vez muerto su esposo. La victoria las trajo a tierras peruanas.

Los años de la postguerra, no obstante, fueron iguales de difíciles. La tarea, ahora, era recuperar los años perdidos y, al mismo tiempo reconstruir el panorama devastado. Empezaba así la búsqueda de otras y nuevas oportunidades, las cuales exigían asimismo nuevas reubicaciones. En general, no fueron pocos los obstáculos que tuvieron que atravesar los judíos e inmigrantes europeos para establecerse en tierras americanas debido a las restricciones que los distintos gobiernos incluían en sus políticas de inmigración.

En Perú, los inmigrantes judíos aprendieron el castellano rápidamente; entraron a trabajar a diversas clases de empresas (textiles, madereras para dar algunos ejemplos); se desempeñaron en diversos oficios; incursionaron en prósperos comercios; se integraron en su comunidad religiosa; se casaron y se insertaron a la sociedad peruana.

Hoy en día, aunque el recuerdo de una etapa de sus vidas que les quedó trunca constituya un estigma doloroso, reconocen la tranquilidad que en territorios peruanos han podido encontrar y, sin amargura, aprendieron a levantarse a base de puro esfuerzo, trabajo y mucho sacrificio.

A través de todos los relatos presentados, hemos obtenido información acerca de los sucesos que acompañaron el desplazamiento de los inmigrantes judíos a Perú, configurando así la memoria de quienes, por determinadas circunstancias, tuvieron que dejar sus lugares de origen, trasladándose, bien motivados por un espíritu de aventura o bien forzados por la violencia, dejando atrás de manera abrupta una vida, la cual tuvo que ser rehecha completamente en el nuevo destino.

Por eso mismo, en esta segunda parte de nuestra nota, deseamos destacar la importancia y utilidad de todos estos relatos para reconstruir la historia de la presencia judía en Perú, debido a las dificultades encontradas al tratar de encontrar evidencias escritas que nos hablen en forma continua de una identidad judía desde que se produjo la llegada de los primeros judíos a este país.

Realizar un trabajo histórico que, efectivamente, incluya a la diversidad y, con ello, a los puntos de vista tradicionalmente excluidos por la vieja y anquilosada historia oficial implica realizar un paréntesis para señalar, precisamente, la larga data de la presencia judía en Perú y de qué manera la historia oral ayuda como herramienta metodológica en este proceso.

Los tiempos del dominio español en América trajeron a una serie de inmigrantes o cristianos nuevos de origen sefardí, llamados "marranos" y 
considerados de procedencia dudosa tanto por sus antecendentes religiosos como por sus prácticas cripto-judías. No es difícil suponer entonces que, para dichos inmigrantes, el "nuevo mundo" haya constituido una alternativa o escapatoria hacia la liberación frente al decreto de expulsión (1492) y a la persecución inquisitorial de la que los judíos fueron objeto en la península Ibérica. Sin embargo, nunca hubo declaración abierta ni expresa alguna acerca de su verdadera profesión religiosa de parte de estos judeoconversos o cristianos nuevos por temor, ya sea a la represión, ya sea a las confiscaciones inquisitoriales, de las cuales, tampoco, se libraron en tierras de ultramar.

Desde la segunda mitad del siglo diecisiete hasta aproximadamente las tres primeras décadas del siglo veinte, se observa una notable disminución de las fuentes para la historia de los judíos (Liebman 1984: 165) en Perú; en tanto que un nuevo proceso de inmigración judía al continente americano, procedente sobre todo de Europa central y oriental, se evidencia hacia la segunda mitad del siglo diecinueve (Avni 1992, Mörner 1989). Igualmente, en este punto, salvo aquellos pocos casos favorecidos por los intentos del gobierno peruano para atraer a europeos blancos, trabajadores, profesionales, comerciantes e inversionistas (Trahtemberg 1987) ${ }^{16}$, así como la experiencia sefardí, procedente de Marruecos, Turquía y Siria alrededor de 1880, la cual dio origen en Iquitos a una cultura "mestizo-judía” (Segal, 1999; Salcedo Mitrani et alii 2002: 15), nos enfrentamos a la escasez, dispersión y poca fiabilidad de las mismas.

El problema persiste en el caso de los judíos arribados durante la primera mitad del siglo veinte. Dentro de este conjunto de inmigraciones individuales, se observa que asquenazíes rusos, polacos y rumanos, así como sefarditas turcos, palestinos, egipcios y sirios llegaron a Perú, en la segunda década del siglo veinte, más por aventura y pensando en mejorar sus condiciones socioeconómicas por las oportunidades y riquezas que "el sur" presentaba. Los registros migratorios en este último caso consignan tan sólo la procedencia del país o nacionalidad y datos personales de los inmigrantes (edad, nombres, sexo, ocupación entre otros), mas no informan acerca de la práctica religiosa o credo de los mismos. Algo similar ocurre con los judíos de la segunda mitad del siglo veinte, muchos de los cuales, en el contexto de la guerra, se trasladaban alterando sus verdaderas identidades.

Tales circunstancias constituyen evidentes obstáculos para la reconstrucción histórica de la presencia judía en Perú. Por otro lado, los aportes que consideran la historia judía como un proceso reciente de la segunda mitad del siglo

\footnotetext{
16 Algunos de estos ejemplos, referidos por Trahtemberg, son Wladyslaw Kluger quien llegó en 1848 para organizar la Escuela Politécnica de Lima, construyendo en 1876 el ferrocarril PerúBoliva; en 1860, llegaron los hermanos Segismundo y Fernando Jacobi como agentes de bolsa, enviados por los Rotschild; Max Bromberg vino en 1865 y fue el primer judío que se casó con un joven peruana católica.
} 
diecinueve (Böhm 1985; Marazzani Mindreau 1970; Trahtemberg 1987, 1989; Segal 1999), junto a otros textos de carácter literario (Isaac Goldemberg 1989, 1992, 2001), archivos fotográficos (Salcedo Mitrani et alii 2002) y documentales (Ackerman 2008 ${ }^{17}$, Salcedo Mitrani 2008), los cuales abarcan solamente ciertos periodos del siglo veinte, segmentan la historia judía en Perú y la reducen a tan sólo ciento cincuenta años atrás aproximadamente, poco más o poco menos, con lo cual se desvincula, dicha historia, de sus primeros antecedentes sefardíes coloniales y se deja de lado un aporte o patrimonio representativo que abre la posibilidad a la construcción de una identidad judía peruana en forma continua, cuyas características están en función directa a la historia de las inmigraciones en Perú, iniciada con los viajes de Colón.

Nuestra propuesta aquí es enfatizar en el uso y aplicación de la historia oral como herramienta de investigación histórica que sea capaz de registrar, por ejemplo, aquellas versiones orales populares sobre el asentamiento en Celendín, ciudad peruana, ubicada en la región Cajamarca (Wachtel 2001: 331; Seymour B. Liebman 1984: 177), de un grupo de portugueses de origen judíosefardí que huían de las acciones inquisitoriales del Tribunal del Santo Oficio o estudiar el sincretismo religioso de los judíos mestizos de Iquitos (Segal 1999).

La contribución de la historia oral así descrita puede completar los vacíos encontrados en los documentos sobre procesos y confiscaciones inquisitoriales tanto como ensanchar la visión de los trabajos más recientes, ya conocidos, sobre la inmigración judía en los siglos diecinueve y veinte, constituyendo, parte importante del insumo requerido para elaborar la respuesta a la pregunta ¿qué es ser judío en el Perú?, frecuentemente formulada por quienes se ocupan de la materia.

\section{Referencias bibliográficas}

AVNI, Haim (1992). Judíos en América. Madrid, Editorial MAPFRE.

BAZÁN COQUIS, Adolfo (1999). "Nos mataron por toda Europa” en El Comercio, 18 de mayo, a20.

BÖHM, Günther (1985). Judíos en el Perú durante el siglo XIX. Santiago, Editorial Universitaria.

GOLDEMBERG, Isaac (1980). La vida a plazos de Jacobo Lerner. Hanover, Ediciones del Norte.

GOLDEMBERG, Isaac (1992). La vida al contado. Hanover, Ediciones del Norte.

GOLDEMBERG, Isaac (2001). El nombre del padre. Lima, Santillana.

KARL, Mali (1999). Escape a la vida. Lima, Imprenta Charito.

17 http://www.youtube.com/watch?v=rw29A7Qz1Ps. Consultado el sábado 13 de noviembre de 2010, 12 horas. El documental sobre los sobrevivientes judíos de la persecución nazi radicados en Perú de Delia Ackerman, Volviendo a la luz, fue presentado en el Festival de Lima o Encuentro Latinoamericano de Cine de Lima 2008.

LETRAS 81 (116), 2010 
LIEBMAN, Seymour B. (1984). Réquiem por los olvidados. Los judíos españoles en América 1493-1825. Madrid, Altalena Editores.

MARAZZANI MINDREAU, Emilio (1970). 1870-1970: Cien años de vida judía en el Perú. Lima.

MÖRNER, Magnus (1989). Aventureros y proletario. Los emigrantes en Hispanoamérica. Madrid, Editorial MAPFRE.

TRAHTEMBERG SIEDERER, León (1987). La inmigración judía al Perú 1848-1948. Lima. (1989). Los judíos de Lima y las provincias del Perú. Lima.

SALCEDO MITRANI, Lorry (2008). Fire within. Video, Lima.

SALCEDO MITRANI, Lorry y Henry MITRANI (2002). El eterno retorno. Retrato de la comunidad judio-peruana. Lima, Fondo Editorial del Congreso del Perú.

SEGAL FREILICH, Ariel (1999). Jews of the Amazon. Self-Exile in the Earthly Paradise. Filadelfia, Jewish Publication Society.

WACHTEL, Nathan (2001). La foi du souvenir. Labyrinthes marranes. París, Éditions du Seuil. 